\title{
Optimizing Health Management through Circadian Feed Intake Rhythms: A Prognostic SciTech
}

\section{Akbar Nikkhah*}

Chief Highly Distinguished Professor, Department of Animal Sciences, Faculty of Agricultural Sciences, University of Zanjan, 313-45195, Iran

This editorial conceptually develops and discusses the significance of circadian feed intake rhythms as a feasible management tool to monitor animal health. Realistically, circadian and periprandial feed intake patterns must be quantified to enable accurate monitoring of feeding behavior and reliable predictions of feed intake in highproducing ruminants [1-3]. Circadian and day-to-day changes in intake rhythms would greatly reflect changes in rhythms of behavior and metabolism. The latter stem from and determine productivity and health $[3,4]$. For instance, a 10-min drop in daily eating time of dairy cows during the periparturient transition period may be linked to a twotime increase in diagnosis likelihood for metritis [5]. Evidence exists that dairy cows prone to metabolic disorders exhibit characteristic changes in feeding behavior (i.e., daily eating duration, eating rate, number of meals, number of bunk visits) [6]. Innovatively, this article elaborates on changes in circadian and periprandial rhythms of feed intake as possible biomarkers of physiology and certainly health.

Feed delivery is a major regulator of circadian rhythms in feed intake of lactating cows $[7,8]$. The stimulatory effects of feed delivery on eating persist even with multiple daily feeding [7]. The elongated eating time of cows fed twice daily appears to be mostly due to increased eating time overnight and before sunrise. In addition, cows fed four times daily tended to spend more time eating in evening than in morning. Most recent studies, also, suggest that evening instead of morning feed delivery in once-daily fed lactating cows under thermoneutral conditions increased eating rate and feed intake within certain periods shortly post-feeding and, as a result, increased milk production $[9,10]$. These findings suggest that dairy cows consume much when fresh feed is presented and that the amount of feed consumed after feed delivery depends on time of day [10]. Thus, should the increased production persist long enough, it must be due to improved metabolism, health and comfort. This cascade helps to develop a theory that monitoring daily and weekly changes in circadian (i.e., almost within a 24 -h period) feed intake rhythms can serve as an early indicator of metabolic health.

The recent emerging science proposes that should cows anticipate feed delivery and feeding time, higher peaks in eating durations may occur. This indicates that cows consume more feed more rapidly through craving when they forecast fresh feed delivery [10]. As such, circulating insulin and glucose were respectively higher and lower shortly post-feeding when cows were fed in evening vs. morning [3]. In other words, dairy cows seem to more accurately memorize night vs. day feeding. Higher insulin could mean reduced glucagon effects, and thus, reduced gluconeogenesis. Accordingly, the higher circulating insulin and lower glucose shortly post-feeding (in evening-fed cows) may postpone the glucagon-driven satiety and, as a result, contribute to the more rapid eating in cows fed in evening vs. morning. Therefore, altered circadian rhythms of feed intake by altering feeding and housing management alter circadian rhythms of production and ultimately affect animal health and welfare.

Altogether, within a well-established management system, any changes in circadian rhythms of feed intake daily, weekly and even monthly should inform about health status both retrospectively and indeed prospectively. This information offers a prognostic merit for feed intake rhythms in livestock health management. More data on interconnections of circadian, daily and weekly changes in feed intake rhythms are required before clear-cut quantitative relations can be globally formulated.

\section{Acknowledgements}

The Ministry of Science Research and Technology, National Elite Foundation, and University of Zanjan, Iran, are thankfully acknowledged for supporting the author's global programs of optimizing science education in the new millennium.

\section{References}

1. Nikkhah A (2014) Ruminant intake orchestration: An inter-science chronophysiological discipline. J Vet Sci Technol 5: e112.

2. Nikkhah A (2014) Food intake circadian chronology: A healthy rising science. J Nutr Health Sci 1: 202.

3. Nikkhah A (2013) Time of feed provision (2100 vs. 0900 h) orchestrates postprandial rhythms of food intake and peripheral glucose in lactating cows. Biol Rhythm Res 44: 33-44.

4. Nikkhah A (2014) Managing nutritional disorders by timing of food observation and ingestion: Insights from dairy science. Int. J. Dairy Sci. Process 2: 1-2

5. Urton G, von Keyserlingk MAG, Weary DM (2005) Feeding behavior identifies dairy cows at risk for metritis. J Dairy Sci 88: 2843-2849.

6. Gonza lez LA, Tolkamp BJ, Coffey MP, Ferret A, Kyriazakis I (2008) Changes in feeding behavior as possible indicators for the automatic monitoring of health disorders in dairy cows. J Dairy Sci 91: 1017-1028.

7. De Vries TJ, von Keyserlingk MAG, Beauchemin KA (2005) Frequency of feed delivery affects the behavior of lactating dairy cows. Journal of Dairy Science 88: 3553-3562.

8. Nikkhah A (2011) Time of feeding an evolutionary science, Lap Lambert Publishing, GmbH \& Co. KG, Germany.

9. Nikkhah A, Furedi C, Kennedy A, Wittenberg K, Plaizier JC (2010) Morning vs evening feed delivery for lactating dairy cows. Can J Anim Sci 91: 113-122.

10. Nikkhah A, Furedi C, Kennedy A, Crow G, Plaizier J (2008) Effects of feed delivery time on feed intake, rumen fermentation, blood metabolites and productivity of lactating cows. J Dairy Sci 91: 1-12.

*Corresponding author: Akbar Nikkhah, Chief Highly Distinguished Professor Department of Animal Sciences, Faculty of Agricultural Sciences, University of Zanjan, 313-45195, Iran, Tel: 0098-241-5152801; Fax: 0098-241-5152204l; E-mail: anikkha@yahoo.com

Received January 11, 2015; Accepted January 28, 2015; Published January 30 2015

Citation: Nikkhah A (2015) Optimizing Health Management through Circadian Feed Intake Rhythms: A Prognostic SciTech. J Veterinar Sci Technol 6: e115. doi:10.4172/2157-7579.1000e115

Copyright: (c) 2015 Nikkhah A. This is an open-access article distributed unde the terms of the Creative Commons Attribution License, which permits unrestricted use, distribution, and reproduction in any medium, provided the original author and source are credited. 